\title{
How to Motivate People Working in Teams
}

\author{
Xin Jiang \\ School of Foreign Languages, Changzhou Institute of Technology \\ Tong Jiang South Road No. 299, Changzhou 213002, Jiangsu, China \\ E-mail: jiangx@czu.cn
}

\begin{abstract}
This article focuses on the benefits of teamwork. The research objective is to explore how to motivate people working in teams. The study includes secondary research to gather data and add to existing knowledge. This article concludes with suggestions for improving team performance by improving motivation. These include objective-based team training, voluntarily formed teams, team-based leadership and communication system. As far as future research is concerned, motivation methods in cross-cultural situations might be a valuable area for further research.
\end{abstract}

Keywords: Team work, Motivation, Training, Leadership, Communication, Empowerment, Reward

\section{Introduction}

"All organizations are concerned with what should be done to achieve sustained high levels of performance through people." (Armstrong, 2001, p.155)

Motivation theory is one of the most important theories in Human Resource Management (HRM). It explains what organizations can do to encourage people to apply their efforts and abilities in ways that will further the achievement of the organization's goals as well as satisfying their own needs (Armstrong, 2001, p. 155). There are a number of methods to motivate people such as rewards, punishments, actions to satisfy needs, psychological processes, etc.

Along with the rapid development of the world, highly cooperated working styles appears such as the new work practice as teamwork with various types of teams: work, parallel, project and management, etc. Nowadays, the use of teams is expanding dramatically in response to competitive challenges. For instance, $82 \%$ of companies with 100 or more employees reported that they use teams (Gordon, 1992).

Teamwork is regarded as the key to staff development (Beal, 2003) and businesses would benefit from successfully motivating people working in teams. This paper focuses on benefits and approaches of motivating people working in teams depending on different situations.

Teamwork is prevalent at present, especially in the work place. This shows that teamwork is very effective and beneficial for a business to grow. Compared with the working style in the UK today, work practice in China is more individual and teamwork is a relatively new area there. Furthermore, teamwork and motivation is very important for the operation of successful organizations and a greater understanding of management.

\section{Literature Review}

The environment is unexpected and changing constantly because of the rapid development of technology. In particular, businesses confront fierce competition. Accordingly, if a business wants to succeed in business circles and to be a leading organisation, it must be highly aware of its effectiveness and productivities and make good use of its resources in order to achieve business excellence (Samson and Challis, 2002).

It is well known that personnel are most important resources which can undoubtedly have strong effects on an overall objective of an organisation. Furthermore, work performance is vital for business growth. As a result, it is essential for a business to explore some new methodologies in HRM areas, in order to benefit the long-term development of a business.

HRM as a fundamental functional area in an organisation is required to make sure of keeping high work effectiveness and high level performance, aiming at sustainable development of a whole business. In today's organisations, since employee motivation is getting more and more difficult, there is a need to discover more effective motivators rather than just conducting monetary incentives.

Teamwork as one of the new working practices in HRM fields is prevalent nowadays and significant benefits can be gained from teamwork. According to Cohen and Bailey (1997, p. 241), 
"A team is a collection of individuals who are interdependent in their tasks, who share responsibility for outcomes, who see themselves and who are seen by others as an intact social entity embedded in one or more larger social systems (for example, business unit or the corporation), and who manage their relationships across organisational boundaries." (Cohen and Bailey, 1997, p. 241)

However, it was also found that people who work in teams sometimes lack of enthusiasm and sufficient cooperation. Sequentially, such a phenomenon might have a negative impact on a business and hold back an organisation. Accordingly, it is necessary to find out some effective measures for solving such problems so as to take advantages of teamwork.

\section{Benefits of Teamwork}

Teamwork is the key to staff development (Beal, 2003). Teamwork can be smartest strategy for growth (Krotz, 2003). Teamwork can influence performance results and organisational objectives (Brown, 1995). Teamwork can improve social relations to overcome the sense of separation and low trust syndrome (Jin, 1993).

Teamwork can make people share the same goals and responsibilities for outcomes, namely, the common objective of an organization. Teamwork can also enhance effectiveness and productivity of a company, which would gain an organisation more profit (Beal, 2003).

\section{Motivation Theory}

According to Armstrong, a motive is a reason for doing something. Motivation is concerned with the factors that influence people to behave in certain ways. Motivation theory examines the process of motivation and explains why people at work behave in the way they do in terms of their efforts. It also describes how to encourage people to apply their efforts and abilities to achieve the organisation's goals as well as satisfy their own needs. (Armstrong, 2001, p. 155-156)

\subsection{Different Motivation Methods}

At present, there are a number of approaches of motivating people working in teams, such as, trust, justice, leadership, empowerment, 360-degree feedback, team-based rewards, ongoing learning, etc (Kiffin-Petersen and Cordery, 2003; Shapiro and Kirkman, 1999; Tjosvold and Wong, 2000; Margulies and Kleiner, 1995; Khanna, 2000; Brown, 1995; Ober, Yanowitz and Kantor, 1997).

\subsubsection{Various Types of Teams}

There are various types of teams such as work teams, parallel teams, project teams and management teams, etc. Different types of teams require different motivation methods. (Cohen and Bailey, 1997)

Currently, there are other new kinds of teams used in practice such as autonomous work teams. Autonomy is proved to be associated with higher performance for work teams (Cohen and Bailey, 1997). It reflects that job autonomy is positively related to job satisfaction and employee performance motivation (Kiffin-Petersen and Cordery, 2003). It appears an autonomous work group (AWG) and a self-managed work team (SMWT) develops responsibilities and satisfy human needs (Margulies and Kleiner, 1995).

For instance, compared to work teams with assigned members, voluntarily formed work teams have higher work motivation and better performance. It appears that members in voluntarily formed groups often spontaneously gather together at work even in leisure time. Most members share responsibilities, aiming at raising both quantity and quality of productivity through concerned efforts. It also indicates with a warm and friendly atmosphere, team members could complement each other's skills via comfortable discussions, which make them feel competent and self-determining. Consequently, innovations occurred through such cooperative work activities. (Jin, 1993)

Conversely, a non-voluntary group formation tends to result in weaker individual adherence to work units, less share commitment to teams, have slighter interests in daily work and lower cooperative and innovative (Jin, 1993).

\subsubsection{Employees' Attitudes towards Teamwork}

Employee resistance to teams is recognized as a key constraint on the success of an organisation and will diminish team effectiveness. Trust in both co-workers and management is considered as predictors of employee's preference for teamwork. It suggests trust in co-workers and management is positively associated with organisational outcomes (Kiffin-Petersen and Cordery, 2003).

Secondly, individual team members who are provided with opportunities to learn and utilize new skills will have more favorable attitudes towards teamwork (Kiffin-Petersen and Cordery, 2003). 
Third, cultural values such as individualism and collectivism have an effect on employees' preference for teams. For example, China is characterized as collectivism and Chinese believe "trust, cooperation, reciprocity and harmony" are essential for success. Thus, compared with highly individualistic America, Chinese employees prefer teamwork more than Americans. (Jin, 1993)

Finally, anticipatory injustice is positively related to change-resistance and turnover intentions, which could also have negative effect on employees' commitment. It shows that employees often resist the move to teams because they would anticipate distributive injustice and fear the change to teams might be a smokescreen for layoffs. Moreover, employees also fear that working in teams would increase confrontations with co-workers. Under such circumstances, employees are likely to resist the change to work in teams; even worse, they might reduce their organisational commitment or quit their jobs. Therefore, it is very difficult to motivate people working in teams with the influence of distributive injustice. As examined, procedural justice could moderate employees' negative reactions. However, it suggests that obtaining high levels of anticipatory justice is likely to be difficult in a business world. (Shapiro and Kirkman, 1999)

\subsubsection{Training in Teams}

Armstrong states, "Training is the formal and systematic modification of behavior through learning which occurs as a result of education, instruction, development and planned experience" (Armstrong, 2001, p. 543). Lawler also states the need for people with the right skills and knowledge who are motivated to perform effectively (Lawler, 2003).

It appears that skill-based teamwork could create an ongoing learning culture for an organization because it could encourage team members to learn. According to Beal, training needs to meet an overall goal of a firm with equal opportunities given to team members. As a consequence, everyone in teams would understand aims of an organisation clearly and be happy to pass their skills and knowledge so as to push the whole organisation forward. (Beal, 2003)

\subsubsection{Leadership in Teams}

As Jin states, employees feel tired under unsatisfactory leaders and they wish to select leaders after their own heart (Jin, 1993). Leadership is a special contribution to an organisation. A manager is a leader who could influence employees greatly and inspire them to perform properly in an organisation. Provided that coordinate relationships are established between managers and employees, it could help to reflect work performance clearly and achieve high performace eventually (Tjosvold and Wong, 2000).

\subsubsection{Empowerment in Teams}

Empowerment is the idea that employees and groups can achieve higher levels of productivity, quality and team member satisfaction through delegation of more task-related decisions to the team. Empowerment as a new design of work groups creates higher levels of job satisfaction, growth and self-actualization (Margulies and Kleiner, 1995). Empowerment provides team members a sense as owners of the organisation, which could get them highly involved and increase their cooperative and innovative abilities.

\subsubsection{Communication Systems in Teams}

Improved communication systems help employees to understand what is expected of them and encourage employees to take more responsibility for their skill levels and performance. Appraisals, department meetings and information chats are different sorts of communication forms for managers to set clear personal objectives for individual employees, because employees can get feedback on their performance at regular team meetings and know their strengths and weaknesses clearly for future improvement. (Beal, 2003) Additionally, positive feedback for team members can help to achieve high level cooperation (Jin, 1993).

Armstrong states, "360-degree feedback is a relatively new feature of performance management" (Armstrong, 2001, p. 503). 360-degree feedback is a performance appraisal tool which includes feedback from superiors, peers, internal and external customers, subordinates and even self-appraisal (Khanna, 2000). It demonstrates that 360-degree feedback makes the appraisal process more efficient and opens communication within the system. Furthermore, this form of feedback could identify training and development needed and boost productivity by giving employees a more accurate sense of their personal strengths and weaknesses (Khanna, 2000).

However, as for a reward system, there is a risk that employees may give one another inflated grades if 360-degree feedback is used to determine pay raises or promotion (Khanna, 2000). Therefore, 360-degree feedback is not suitable for pay decisions. 


\subsubsection{Reward Systems in Teams}

According to Armstrong (2001, p. 623), a reward strategy can develop teamwork. Lawler states, "Reward systems can support change and motivate people to accept change and gain the skills that fit the changing nature of the business" (Lawler, 2003). Numerous rewards systems operate within organisations, often used as a key management tool that can improve a firm's effectiveness by influencing individual and group behavior (Lawler and Cohen, 1992). Rewards are effective for encouraging employees to contribute ideas and participate in improvement process.

With the growing emphasis on teamwork, many organisations are seeking better ways to link teamwork with compensation (Kerrin and Oliver, 2002), for example, team-based rewards and individual-based rewards. Team based rewards can support team-based structures and foster team cooperation (Tjosvold, 1986). Individual-based rewards include individual performance-related pay and skill-based pay (Kerrin and Oliver, 2002). It shows that between 20 and $25 \%$ of UK organisations now operate team-based pay and $25 \%$ of shop-floor individual incentive plans are replaced by team schemes. Compared with the UK, gain-sharing and various forms of small group incentive in the US are growing faster. (Brown, 1995) It appears that team-based rewards affect business performance, competitiveness and effectiveness and it also influences employee involvement, communication and commitment (Kerrin and Oliver, 2002).

It suggests that rather than choosing either individual or group-based incentives, a combination of the two incentive strategies may be more effective in motivating performance at the individual level and co-operation at the team level (Kerrin and Oliver, 2002). However, team-based rewards may foster competition between teams, encouraging teams to focus on their own performance rather than assist or share information with other teams (Mohrman, 1992).

\subsection{Different Motivation Approaches in Different Situations}

Business is required to be very aware of the changes such as an unanticipated crisis which can hold back a firm (Ober, Yanowitz and Kantor, 1997) and notice cultural differences when using motivation methods under different circumstances (DeVoe and Iyengar, 2004). On the other hand, managers should be proactive rather than reactive to think of various issues that may occur in advance so as to carry out accurate measures for motivating employees and achieve a company's targets.

\subsubsection{Teamwork in Crisis}

Although significant benefits can be gained from teamwork, there might be some problems when companies face tough decisions and challenges. At a time of crisis, team-players may not want to face up to reality, which can lead to frustration, flat sales growth and lower profits (Ober, Yanowitz and Kantor, 1997).

As examined, when confronted with a crisis, the key to long-term improvement are various structures, on-going learning processes, reflecting on results and insights gained. Besides, ongoing learning process is found to be effective for problem solving. One suggests that with continuous learning and ongoing reflection on results, a team can shift its orientation from knowing to learning; thereby increasing its ability to produce desired business results. (Ober, Yanowitz and Kantor, 1997)

\subsubsection{Teamwork in Cross-cultural Issues}

Different countries have different cultures. Therefore, the relationship between managers' perceptions of employee motivation and performance appraisal differs in cultural regions. Motivation includes two types, one is intrinsic motivation, the other is extrinsic motivation (Herzberg, 1957). According to The Human Side of Enterprise, McGregor (1960) divides mangers into two camps: Theory X manager and Theory Y manager. Theory $\mathrm{X}$ and Theory $\mathrm{Y}$ is the primary source of motivation must lie intrinsic or extrinsic to employees. As a consequence of different cultures, managers from North America, Asia and Latin America have different perceptions of motivation.

North American managers will perceive their employees as being more extrinsically than intrinsically motivated in contrast to their employees who perceive themselves as being more intrinsically than extrinsically motivated. The reason for using such a motivation method in North America is North Americans adopt "the norm of pay", bring a "market orientation" to their interpersonal relations and tend to preclude the consideration of socio-emotional dimensions in workplace. (DeVoe and Iyengar, 2004)

However, in Asian culture, collectivism dominates social norms and values. Accordingly, Asians are more likely to draw on both internal and external causes when explaining behaviors of others. Both Asian managers and their employees will perceive motivation as being equally derived from intrinsic and extrinsic factors. (DeVoe and 
Iyengar, 2004)

Unlike North Americans and Asians, Latin American managers might be more attuned to perceptions of their employees. Thus, both groups perceive motivation as being more intrinsically than extrinsically derived. (DeVoe and Iyengar, 2004) It can be safely concluded that because of different cultures, motivation approaches are different in different cultural regions.

\section{Research Questions}

With in this context, this dissertation is concerned with the benefits of motivating team members and the methods to doing so. In investigating these research questions, one will also examine the situational factors that need to be considered when motivating team members.

\section{Methodology}

As for the methodology applying to this dissertation, a secondary research was conducted, using information sources such as the Journal of Organizational Change Management, the Journal of Management, Leadership \& Organization Development Journal, Management Development Review, The International Journal of Human Resource Management, and Personnel Review.

The strength of a secondary research is simple, convenient and time efficient. Moreover, on the DME program, students have only a couple of months to do the project. Thus, it is a very suitable method for us to gather data.

The limitation of such methods is that the data used in the dissertation is not original. Unlike primary research, this method can not help in the development of new ideas. However, the key to beneficial research is to find something totally or at least slightly different and new, so that it can further our knowledge in a particular subject.

This dissertation is concerned with the benefits of motivating people working in teams. As for the primary research it needs to design some questionnaires for gathering quantitative and qualitative information. Prior to the real survey, the questions would be well designed in order to avoid problems such as surveys without responses or inaccurate answers (Allen, 1975, p. 58).

It would need a pilot study in order to achieve the objective. Questionnaires would disclose the information that is common and encourage respondents to provide real and precise information (Allen, 1975, p. 51). Furthermore, the questionnaires would be distributed to employees in some multinational companies, containing the following aspects: attitudes towards teamwork, team-based reward system, individually-based pay, empowerment, teamwork between leaders and employees, feedback system, justice and injustice, learning organizations, and cross-cultural issues and so on. Most of the questions would be multiple choices. At the end of the questionnaire, it would provide a subjective question investigating the attitudes towards teamwork, for example, whether it is good or bad.

Aside from questionnaires, it would also need some interviews using simple random sampling as my research tool (Allen, 1975, p. 51). Therefore, the research results could be more accurate and unpredictable, and such methodologies could also make the results of the survey more interesting. Before conducting such a survey, it would select employees from different job characteristics randomly and then conduct the interview privately and separately. In the meantime, it would also record the whole interview for my further studies and try to make the research more rigorous.

For example, it would interview some employees as well as some leaders, who might be in the same companies or come from different companies or different countries. The content of the interview would hide the question itself, using the third person and randomized techniques. It would also provide response categories and both sensitive and insensitive questions to get the true answer (Allen, 1975, p. 53). It is known that when people are interviewed, they easily feel nervous and sometimes even feel embarrassed if the interview is not well structured. Consequently, it is necessary and important to make sure that respondents would provide the true answer unconsciously before the interview. In other words, the interview is supposed to be feasible. Otherwise, the interview would not progress successfully. As a result, it would not gather appropriate data.

The two procedures of the survey mentioned above are the initial thinking about the future research, which would help to gather quantitative and qualitative information for contributing to the primary research and also give some new and interesting findings to add to the current dissertation.

\section{Conclusion and Recommendations}

As discussed, motivation methods for team members from different perspectives are interrelated and interacted. There are several motivation methods put forward as follows, which are integrated in practice for motivating 
people working in teams.

\subsection{Objective-based team training with equal opportunities}

An organisation is required to train teams aiming at an overall goal of its business with equal opportunities given to every group. Objective-based team training aims to make team members aware both of their own goals as well as those of the company. Through objective-based training, team members can understand clearly about their individual tasks as well as their team objectives. Such training would create team spirit, make team members understand how important they are and believe they have sufficient capabilities to improve organisational development via excellent teamwork.

As a result, it could encourage team members to contribute to teams so as to achieve the common goal of team-based organisation (Kerrin and Oliver, 2002).

\subsection{Voluntarily formed team formation in ongoing learning process}

According to Jin (1993), voluntarily formed teams could create a friendly atmosphere among team members and stimulate employees' preference to work as teams. I strongly agree with his points of view.

Voluntarily formed team formation empowers team members and increases their involvement. Secondly, it makes team members willing to learn from each other and share skills, experience, knowledge and information. Third, it is likely to gather people with similar backgrounds and the same type to form homogeneous teams which can achieve optimal outcomes (Prat, 2002).

Simultaneously, with ongoing learning process, team members would improve their abilities to learn incrementally by helping each other. Additionally, ongoing learning process could create a learning organisation, because it urges employees to learn continuously (Ober, Yanowitz and Kantor, 1997; Armstrong, 2001, p. 523).

\subsection{Team-based leadership and communication system}

Managers as leaders in organisations have the ability to influence employees. Therefore, to create close relationships between managers and employees in the form of teamwork could affect employees' behaviour and strengthen communication system.

On the one hand, managers could gain the information on team performance directly and discover the problems in time. On the other hand, team members would receive feedback about how their work is going conveniently and know clearly about their strengths and weaknesses for further improvement.

This motivation method could easily stimulate team members to follow managers' instructions for high performance by applying the art of leadership and help to achieve team excellence and sustained development by keeping team strengths and solving team problems quickly.

\subsection{A mixed reward system}

Armstrong states, p. 626

Krotz states, "When companies recognize teamwork with tangible rewards, they become more productive and better at retaining employees" (Krotz, 2003).

A mixed reward system can be applied in motivating team members. This consists of individual performance-based pay, team goal-based pay and skill-based pay (Armstrong, 2001, p. 615; Hoffman and Rogelberg, 1998). Various reward methods in this mixed reward system integrates and shifts according to different situations.

For instance, team members could be well rewarded depending on individual performance or contribution to teams, which could encourage team members to try their best to work for teams. Team as a whole could be rewarded when achieving required objectives, which could drive team members to work hard and great responsibility sharing as well as team co-operation. Skill-based pay could support to attract and retain skilled people as excellent team members or team leaders and help to create a better learning organisation (Armstrong, 2001, p. 523) by influencing and forcing other team members to learn.

Secondary research was one of the research methods conducted in this dissertation. Since the time for the research is limited and some journal articles of high quality must be paid for, the secondary research is also limited. Sufficient time and easy access to gather information are suggested to be provided for future research as well as conducting primary research activities.

Finally, there are some new questions raised during the research. One of the key questions for future study refers to how to motivate team members in cross-cultural situations. The other is how to motivate co-operations among 
teams. These questions would be beneficial for business studies and enrich the HRM theory as there has been a limited amount of research in this area. Primary research such as questionnaires and interviews would be ideal methods to investigate research questions.

\section{References}

Allen, G.R. (1975). The Graduate Students' Guide to Theses and Dissertations, A Practical Manual for Writing and Research. Jossey-Bass Publishers.

Armstrong, M. (2001). A Handbook of Human Resource Management Practice. Eighth Edition, Bath, The Bath Press.

Beal, B. (2003). Teamwork - The Key to Staff Development. Career Development International, 8/5, pp. 235-240.

Brown, D.I. (1995). Team-based Reward Plans. An International Journal, Vol. 1, No. 1

Cohen, S.G., and Bailey, D.E. (1997). What Makes Teams Work: Group Effectiveness Research from the Shop Floor to the Executive Suite. Journal of Management, Vol.23, No. 3, pp. 239-290.

DeVoe, S.E., and Iyengar, S.S. (2004). Managers' Theories of Subordinates: A Cross-cultural Examination of Manager Perceptions of Motivation and Appraisal of Performance. Organizational Behavior and Human Decision Processes, 93, pp. 47-61.

Gordon, J. (1992). Work Teams: How Far Have They Come? Training, (October): 59-65.

Herzberg, FW, Mausner, B., and Snyderman, B. (1957). The Motivation to Work. Wiley, New York.

Hoffman, J.R., and Rogelberg, S.G. (1998). A Guide to Team Incentive Systems. Team Performance Management, Vol. 4, No. 1, pp. 23-32.

Jin, P. (1993). Work Motivation and Productivity in Voluntarily Formed Work Teams: A Field Study in China. Organizational Behavior and Human Decision Processes, 54, pp. 133-155.

Kerrin, M., and Oliver, N. (2002). Collective and Individual Improvement Activities: The Role of Reward Systems. Personnel Review, Vol. 31, No. 3, pp. 320-337.

Khanna, P. (Jan 10, 2000). India: The '360-degree’ Appraisal, Businessline. Islamabad, pg. 1

Kiffin-Petersen, S.A., and Cordery, J.L. (2003). Trust, Individualism and Job Characteristics as Predictors of Employee Preference for Teamwork. The International Journal of Human Resource Management, ISSN 0958-5192, print/ISSN 1446-4399 online.

Krotz, J.L. (2003). Reward Your Employees for Teamwork in 2003. Marketing Intelligence.

Lawler, E.E. (2003). Managing Change. Vision to Venture: Work Team Coaching Bi-weekly, Vol. 1, No. 21.

Lawler, E.E., and Cohen, S.G. (1992). Designing Pay Systems for Teams. ACA Journal, Vol. 1, pp. 6-19.

Margulies, J.S., and Kleiner, B.H. (1995). New Designs of Work Groups: Applications of Empowerment. Empowerment in Organizations, Vol. 3, No. 2, pp. 12-18.

McGregor, D. (1960). The Human Side of Enterprise. New York, McGraw-Hill.

Mohrman, A.M, Mohrman, S.A., and Lawler, E.E. (1992). The Performance Management of Teams, in Bruns, W.J. Jr (Ed.), Performance Measurement, Evaluation, and Incentives. Harvard Business School Press, Boston, MA, pp. 217-41.

Ober, S, Yanowitz, J., and Kantor, D. (1997). Perspective: Is Teamwork Holding Back Your Firm? Management Development Review, Vol. 10, No. 6/7, pp. 239-240.

Prat, A. (2002). Should A Team Be Homogeneous? European Economic Review, 46, pp. 1187-1207.

Samson, D., and Challis, D. (2002). Patterns of Business Excellence. Measuring Business Excellence, Vol. 6, No. 2

Shapiro, D.L., and Kirkman, B.L. (1999). Employees' Reaction to the Change to Work Teams, The Influence of “Anticipatory" Injustice. Journal of Organizational Change Management, Vol. 12, No. 1, pp. 51-66.

Tjosvold, D. (1986). The Dynamics of Interdependence in Organizations. Human Relations, Vol. 39, pp.517-40

Tjosvold, D., and Wong, A.S.H. (2000). The Leadership: Building Teamwork with and among Employees. Leadership \& Organization Development Journal, 21/7, pp. 350-354. 